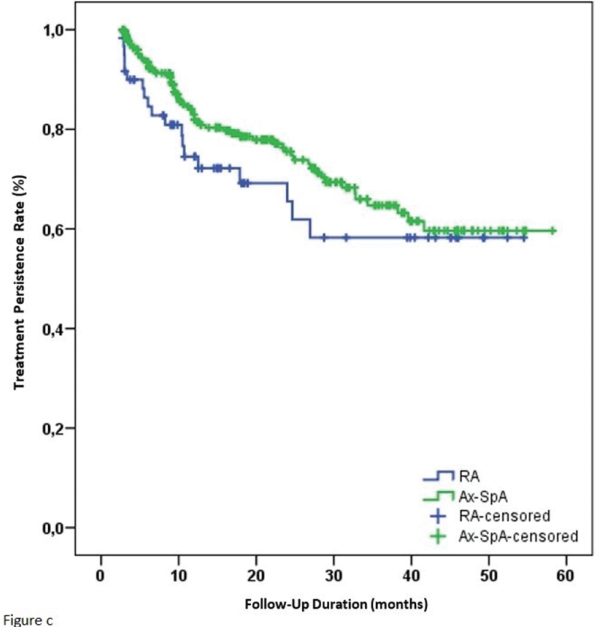

REFERENCES

[1] Strand V, Singh JA. Patient Burden of Axial Spondyloarthritis. J Clin Rheumatol. 2017 Oct;23(7):383-391.

[2] Scott DL, Wolfe F, Huizinga TW. Rheumatoid arthritis. Lancet. 2010 Sep 25;376(9746):1094-108.

[3] Anghel LA, Farcas AM, Oprean RN. Medication adherence and persistence in patients with autoimmune rheumatic diseases: a narrative review. Patient Prefer Adherence. 2018 Jul 3;12:1151-116

Disclosure of Interests: Servet Akar Grant/research support from: MSD, Abbvie, Roche, UCB, Novartis, Pfizer, Amgen, Consultant for: MSD, Abbvie, Roche, UCB, Novartis, Pfizer, Amgen, Speakers bureau: Pfizer, Umut Kalyoncu Grant/research support from: MSD, Roche, UCB, Novartis and Pfizer, Consultant for: MSD, Abbvie, Roche, UCB, Novartis, Pfizer and Abdi Ibrahim, Speakers bureau: MSD, Abbvie, Roche, UCB, Novartis, Pfizer and Abdi Ibrahim, Ediz Dalkılı Grant/research support from: MSD and Abbvie, Consultant for: MSD, Abbvie,Roche, UCB, Pfizer and Novartis, Speakers bureau: MSD, Abbvie,Roche, UCB, Pfizer and Novartis, Hakan Emmungil Grant/research support from: MSD, Roche, Pfizer, Abbvie, Consultant for: Novartis, Roche, Speakers bureau: MSD, Roche, Pfizer, Abbvie,Celltrion, Novartis

DOI: 10.1136/annrheumdis-2019-eular.5674

\section{AB1393-HPR COMPARISON OF THE QUALITY OF LIFE, FUNCTIONAL AND EMOTIONAL STATUS OF INPATIENTS AND OUTPATIENTS WITH RHEUMATIC DISEASES}

Gamze Arın ${ }^{1}$, Aybüke Seven ${ }^{1}$, Yasemin Özel Aslıyüce ${ }^{1}$, Aykut Özçadırcl ${ }^{1}$, Fatma Birgül Kumbaroğlu', Şule Apraş Bilgen ${ }^{2}$, Edibe Ünal ${ }^{1}{ }^{1}{ }^{1}$ Hacettepe University Faculty of Physical Therapy and Rehabilitation, Ankara, Turkey; ${ }^{2}$ Hacettepe University Faculty of Medicine, Department of Rheumatology, Ankara, Turkey

Background: Quality of life, function and emotional status of inpatients with rheumatic diseases may be estimated worse than outpatients. Previous studies had shown that there was a worsening in the emotional state of inpatients (1).

Objectives: The aim of this study is to compare the quality of life, functional and emotional status in inpatients and outpatients with rheumatic diseases.

Methods: The study included 78 patients (inpatient, $n=31$; outpatient, $n$ $=47)$ with rheumatic disease. The Health Assessment Questionnaire (HAQ) (2) and SF-36 (3) were used to evaluate the functionality and quality of life, and the Hospital Anxiety and Depression Scale (HADS) (4) was used to determine their emotional status. The variables were investigated using visual and analytical methods to determine whether or not they are normally disturbed. Since physical function, mental health and general health perception values of SF-36 and HADS-Anxiety were normally distributed, the Students T-test was used to compare these parameters between two groups. Physical role limitation, pain, social status, emotional difficulty, energy viability of SF-36, HAQ and HADS-Depression were not normally distributed. Thus, Mann-Whitney $U$ test was used to compare these scores between two groups.
Results: The mean age of the subjects $(n=78)$ included in the study was 46.0913 .89 years and the mean BMI was 27.59 15.08. There was a significant difference in depression, anxiety and pain and social functioning sub-parameters of SF-36 $(p<0.005)$ but there was no significant difference in other parameters ( $p>0.005)$.

Abstract AB1393HPR Table 1. Comparison of the scores of inpatients and outpatients

\begin{tabular}{lccc}
\hline & $\begin{array}{c}\text { INPATIENTS } \\
(\text { XSD })\end{array}$ & $\begin{array}{c}\text { OUTPATIENTS } \\
(\text { XSD })\end{array}$ & $p$ \\
\hline HAQ & $0,930,82$ & $0,890,68$ & 0,152 \\
HADS-Anxiety & $9,873,8$ & 8,215 & 0,022 \\
HADS-Depression & $9,935,02$ & $7,474,34$ & 0,006 \\
SF-36 Physical Function & $47,9428,42$ & $48,3623,81$ & 0,669 \\
SF-36 Physical Role Limitation & $27,533,7$ & $27,6336,2$ & 0,869 \\
SF-36 Pain & $33,6632,28$ & $54,0721,42$ & 0,011 \\
SF-36 Social Status & $39,5828,63$ & $55,0627,09$ & 0,032 \\
SF-36 Mental Health & 6121,8 & $62,7316,08$ & 0,761 \\
SF-36 Emotional Difficulty & $31,1038,08$ & $33,3243,83$ & 0,717 \\
SF-36 Energy Vitality & $30,8320,63$ & $43,2820,86$ & 0,317 \\
SF-36 General Health & $36,1621,68$ & $47,4716,15$ & 0,393 \\
Perception & & &
\end{tabular}

Conclusion: It was thought that during the period of admission to the hospital, inpatients should be supported in terms of pain management, social functioning and anxiety and, depression as well as taking medication. Besides, caregivers in hospitals should encourage inpatients with regard to maintaining physical activity.

\section{REFERENCES}

[1] Lambert, C. M., Hurst, N. P., Forbes, J. F., Lochhead, A., Macleod, M., \& Nuki, G. (1998). Is day care equivalent to inpatient care for active rheumatoid arthritis? Randomised controlled clinical and economic evaluation. Bmj, 316(7136), 965-969.

[2] Fries JF, Spitz PW, Young DY: The dimensions of health outcomes: the Health Assessment Questionnaire, Disability and Pain Scales. J Rheumatol 9:789-793, 1982

[3] Brazier, J. E., Harper, R., Jones, N. M., O'cathain, A., Thomas, K. J., Usherwood, T., \& Westlake, L. (1992). Validating the SF-36 health survey questionnaire: new outcome measure for primary care. Bmj, 305(6846), 160-164.

[4] Zigmond, A. S., \& Snaith, R. P. (1983). The hospital anxiety and depression scale. Acta psychiatrica scandinavica, 67(6), 361-370.

Disclosure of Interests: None declared

DOI: 10.1136/annrheumdis-2019-eular.7315

\section{AB1394-HPR CAN SUPPORT FROM SIGNIFICANT OTHERS RECUDE SICKNESS ABSENCE IN EARLY RHEUMATOID ARTHRITIS?}

Maria Bergström ${ }^{1}$, Örjan Dahlström ${ }^{2}$, Ingrid Thyberg ${ }^{3,4}$, Mathilda Bjork ${ }^{1,4}{ }^{1}{ }^{1}$ Linkping university, Department of social and welfare studies, Division of occupational therapy, Norrkping, Sweden; ${ }^{2}$ Linkping university, Department of behavioural sciences and learning, Division of psychology, Linkping, Sweden; ${ }^{3}$ Linkping university, Department of clinical and experimental medicine, Division of neuro and inflammation science, Linkping, Sweden; ${ }^{4}$ Region stergtland, Department of rheumatology, Heart and medicine center, Linkping, Sweden

Background: Persons with rheumatoid arthritis (RA) are at higher risk of sickness absence, and the probability of returning to work is lower compared to the general population [1]. In order for persons with RA to continue working, support from the social environment is claimed to be of importance [2]. However, this relation needs to be further investigated. Objectives: To analyze how support from significant others affects the associations between disease related variables (medication, disease activity and activity limitations) at time for RA diagnosis and sickness absence one year after diagnosis.

Methods: Data were collected from 326 (71\% women) patients in working age (18-63 years) included in the Swedish early RA cohort TIRA-2 [3] during 2006-2009. At time of inclusion, mean age was 50 years $(S D=11)$, $89 \%$ were prescribed disease modifying anti-rheumatic drugs (DMARDs), mean disease activity score 28 joint count (DAS28) was $4.73(\mathrm{SD}=1.34)$, and mean score for activity limitation reported by Health Assessment Questionnaire (HAQ) was $0.91(\mathrm{SD}=0.60)$. The number of days with sickness absence during the first year after diagnosis and inclusion was retrieved from the Swedish Social Insurance Agency. Perceived support from significant others, family and friends separately, were self-reported 
by VAS scales, zero indicating no support and 100 indicating full support. The associations of disease activity, activity limitation and DMARD use with sickness absence and how these associations were moderated by support from significant others, were analyzed using zero-inflated negative binomial regression.

Results: Higher activity limitation (HAQ) was associated with lower risk of sickness absence $(p<.001)$ but more days with sickness absence $(p=.001)$. Higher disease activity (DAS28) was associated with lower risk of sickness absence $(p=.003)$. However, when including family support, this association was not significant $(p=.117)$ and associated with higher risk of sickness absence, but the association was weaker with family support $(p=.029)$. Disease activity was also associated with more days of sickness absence $(p=.013)$. The use of DMARDs had no significant relation to sickness absence $(p=.150)$ or number of days with sickness absence $(\mathrm{p}=.852)$. Although, when including support from friends, DMARD use was associated with higher risk of sickness absence $(p=.041)$. However, this association decreased significantly with support from friends $(p=.022)$.

Conclusion: Support from significant others has an impact on previously known relationships between disease activity, use of DMARDs and sickness absence. Hence, support from significant others has the possibility to help decrease sickness absence among persons with RA one year after diagnosis.

\section{REFERENCES}

[1] Hansen, SM., Hetland, ML., Pedersen, J., et al. Work ability in rheumatoid arthritis patients: a register study on the prospective risk of exclusion and probability of returning to work. Rheumatology. 2017;56(7):1135-1143.

[2] Feddersen, H., Kristiansen, TM., Andersen, PT., et al. Construction of meaningful identities in the context of rheumatoid arthritis, motherhood and paid work: a meta-ethnography. Journal of Clinical Nursing. 2017;26(2324):4117-4128

[3] Thyberg, I., Dahlstrm,.., Bjrk, M., et al. Hand pains in women and men in early rheumatoid arthritis, a one year follow-up after diagnosis. The Swedish TIRA project. Disability and Rehabilitation. 2017;39(3):291-300.

Disclosure of Interests: None declared DOI: 10.1136/annrheumdis-2019-eular.2935

\section{AB1395-HPR BURDEN IN CAREGIVERS OF PATIENTS WITH RHEUMATIC CONDITIONS}

Diana Buitrago-Garcia ${ }^{1}$, Laura Villarreal ${ }^{2}$, Michael Cabrera ${ }^{3}$, Pedro SantosMoreno ${ }^{4}$, Fernando Rodriguez ${ }^{5} .{ }^{1}$ Biomab-Center for rheumatoid arthritis, Nursing research, Bogotá, Colombia; ${ }^{2}$ Biomab - Center for rheumatoid arthritis, Psychology, Bogotá, Colombia; ${ }^{3}$ Biomab - Center for rheumatoid arthritis, EHR administration, Bogotá, Colombia; ${ }^{4}$ Biomab - Center for rheumatoid arthritis, Rheumatology, Bogotá, Colombia; ${ }^{5}$ Biomab - Center for rheumatoid arthritis, Patient program coordinator, Bogotá, Colombia

Background: Rheumatoid arthritis (RA) is a chronic, disease that affects more than $1 \%$ of global population, it is a long term condition that causes pain and disability. Evidence had shown that most of the patients are moderately disabled, which brings the necessity of a caregiver to become the patients companion due to its chronic disease. The caregiving role can have an impact in the psychological and physical spheres of the caregivers life.

Objectives: The aim of this study was to explore demographical characteristics and caregiver burden through the Zarit Scale.

Methods: We conducted a cross sectional study in a meeting where caregivers in a rheumatoid arthritis specialized setting. We collected sociodemographic information, and applied the Zarit caregiver burden interview (ZBI) adapted to Spanish. The ZBI includes 22 questions which has 5 responses from 0 (never) to 4 (nearly always), where scores lower than 47 indicated little to no burden, 47 to 55 low burden and $>55$ intense burden. We calculated means, and standard deviations for continuous variables and categorical variables were presented as rates.

Results: We applied a survey to 132 caregivers. Mean age was 52 years SD 19 and $72 \%$ were women, $78 \%$ of them were taking care of a patient with rheumatoid arthritis, $12 \%$ osteoarthrosis $2 \%$ lupus, $2 \%$ osteoporosis the remaining $6 \%$ were caregivers of patients with ankylosing spondylitis, fibromyalgia, Sjogren syndrome. Regarding the time as caregiver $48 \%$ of them had been carrying the task for less than a year, $16 \%$ between two and three years, $18 \%$ for more than three years, and $13 \%$ for more than four years $5 \%$ of them were temporarily caregivers. In our study $85 \%$ of caregivers were a family member while $15 \%$ was a nurse or a non-related person. Zarit mean score was 38.2913, additionally $35 \%$ had a score higher than 41 points. See table 1 .

\begin{tabular}{lcc}
\hline Variable & $\mathrm{n}$ & $\%$ \\
\hline Zarit Score & 9 & \\
$0-21$ (little or no burden) & 82 & 6.34 \\
$22-40$ mild to moderate burden & 43 & 57.75 \\
$41-60$ moderate to severe & & 30.28 \\
burden & 8 & 5.63 \\
$61-88$ severe burden & & \\
\hline
\end{tabular}

Abstract AB1395HPR Table 1. Zarit scale classification

Conclusion: In our study $93 \%$ of our patients reported to have moderate to severe burden; thus, it is important to develop strategies and explore the factors related to burden in caregivers in patient with rheumatoid arthritis.

Disclosure of Interests: Diana Buitrago-Garcia: None declared, Laura Villarreal: None declared, Michael Cabrera: None declared, Pedro SantosMoreno Grant/research support from: Dr Santos has received research grants from Janssen, Abbvie and UCB, Speakers bureau: Dr Santos has received speaker fees from Sanofi, Lilly, Bristol, Pfizer, Abbvie, Janssen and UCB, Fernando Rodriguez: None declared DOI: 10.1136/annrheumdis-2019-eular.6462

\section{AB1396-HPR SEXUAL SATISFACTION AND SEXUAL DYSFUNCTION IN PARTNER OF PATIENTS WITH ANKYLOSING SPONDYLITIS}

S. Yaprak Cetin ${ }^{1}$, Ayse Ayan ${ }^{2}$, Alime Buyuk Gonen ${ }^{1} .{ }^{1}$ Akdeniz University, Department of Physiotherapy and Rehabilitation, Antalya, Turkey; ${ }^{2}$ Antalya Education and Research Hospital, Rheumatology, Antalya, Turkey

Background: Sexual satisfaction is defined as a special experience with biological rules, value judgments and taboos and also is an important indicator of sexual satisfaction, social harmony and physical-mental well being. Sexual dysfunction or reluctance may be psychological, physiological or combination of both. Current studies showed that most of Ankylosing Spondylitis (AS) patients had sexual problems. They have not also severe joint deformities but also have painful intercourse. Therefore decrease in the range of motion of the hip joint due to AS complicates pelvic pain and sexual dysfunction.

Objectives: The aim of study was investigation of sexual satisfaction and sexual dysfunction in partner of patients with AS.

Methods: 50 individuals: 21 female partner of patients with AS with an average age of $40.385 .31,29$ male patner of patients with AS with an average age of 52.375 .84 were included in this study. The male partners were evaluated with the International Index of Erectile Function (IIEF) and the female partners were evaluated with the Female Sexual Function Index (FSFI).

Results: Total score of FSFI was 52.375 .84 (Sexual desire:5.472.01, arousal:11.664.97, orgasm: 8.524 .74 , lubrication:12.005.06, satisfaction: 8.474.49, pain:8.044.17) in female partner. Erectile score of IIEF was 24.356 .65 , orgasm score was 8.853 .28 , sexual desire score was 7.271.70, sexual satisfaction score was 10.373 .86 and general satisfaction score was 8.142 .83 in male partner.

Conclusion: According to the results of the study, female partner had moderate sexual dysfunction, male partner had mild erectil function. This study showed that the sexual functions of female and male partners of patients with AS were affected negatively. Further studies need to assess their pelvic floor symptoms as well.

\section{REFERENCES}

[1] -Aguiar R, Ambrsio C, Cunha I, Barcelos A. Sexuality in spondyloarthritis the impact of the disease Acta Reumatol Port. 2014:39;152-157

[2] -Bal S, Bal K, Turan Y, Deniz G, Grgan A, Berkit IK, Sendur OF. Sexual functions in ankylosing spondylitis. Rheumatol Int 2011; 31:889-894.

[3] -Healey EL, Haywood KL, Jordan KP, Garratt AM, Ryan S, Packham JC. Ankylosing spondylitis and its impact on sexual relationships. Rheumatol 2009; 48(11):1378-1381. 12.

[4] -Demir SE, Rezvani A, Ok S. Assessment of sexual functions in female patients with ankylosing spondylitis compared with healthy controls. Rheumatol Int 2012; 33(1): 57-63. 13. 5-Ozkorumak E, Karkucak M, Civil F, Tiryaki A, Ozden G. Sexual function in male patients with ankylosing spondylitis. Int J Impot Res 2011; 23(6):262-267. 